\title{
LENGUA Y ESTILO EN LA LITERATURA ALJAMIADO-MORISCA
}

\section{LITERATURA DE TIPO TRADICIONAL}

Como ya he señalado en otra ocasión ${ }^{1}$, una aproximación, no externa, sino interna a la literatura aljamiado-morisca nos pone de relieve, ante todo, su carácter tradicional. Para comprender rectamente la literatura de los moriscos es preciso distinguir con claridad entre el estilo individual y el estilo tradicional. En este sentido, la tradicionalidad de un texto ha de concebirse, según ha señalado $\mathrm{R}$. Menéndez Pidal ${ }^{2}$, como una armoniosa cooperación de creaciones individuales y no como una suma de fuerzas colectivas inconscientes. El texto tradicional vive, de esta forma, sometido durante generaciones a una constante re-elaboración y re-creación, en un perpetuo movimiento o cambio. La obra, así concebida, es por definición dinámica. Buena conciencia tenía el Arcipestre de Hita de esta característica del texto tradicional:

Cualquier ome, que l'oya, sy bien trobar supiere, puede más añadir e enmendar si quisiere.

Ande de mano es mano, cualquier que lo pediere.

Como pella las dueñas, tómelo quien podiere.

(Libro de buen amor, 1629)

La obra tradicional crece, se transforma y muere. La multiplicidad y la diversidad de los textos constituyen una especie de "efectos sonoros". Más que una esencia, el texto tradicional es una producción ${ }^{3}$.

${ }^{1}$ A. GALMÉs DE FUENTES, "La literatura española aljamiado-morisca", en Grundriss der romanischen Literaturen de Mittelalters, Heidelberg (en prensa). Resumo aquí, en este primer apartado, algunos conceptos que desarrollo con mayor amplitud en el trabajo citado.

2 Poesía juglaresca y orígenes de las literaturas románicas, Madrid. 1957, pp. 383-384.

${ }^{3}$ Cf. P. Zumthor, Essai de poétique médiévale, Paris, 1972, p. 73; véase también J. KRISTEVA, "Le texte clos", Lang, 12:1968), p. 103. 
Esta ausencia innata de identidad de la obra tradicional comporta, sin duda, un doble indicio notable: la rareza de títulos y el carácter anónimo de los textos, lo que ocurre, por la misma razón, en la mayor parte de las obras medievales. Sabido es que la mayor parte de los títulos que se citan hoy día se deben a los editores modernos. Los textos aljamiados, como los manuscritos tradicionales de la literatura medieval, cuando distinguen globalmente el texto lo hacen por medio de una expresión discursiva o bien se integra el texto en una declaración análoga: "Ésta es la batalla de al-Açiyad i los de Makka kon 1-annabi ( = profeta) Muhammad", o "Ésta es la batalla nonb $b^{2}$ rada $\mathrm{i}^{\mathrm{y}}$-im entada del Yanbuk, la ku"val al fuwe disipadera de los servidores de la $\mathrm{k}^{\mathrm{k}} \mathrm{ruz}$; en la ku'al adelante se kontarán sus maravillas, i la ventura ke Al.lah puso en-ellos", anuncian el comienzo de sendos capítulos del manuscrito aljamiado que yo he titulado Libro de las batallas 4 , del mismo modo, por ejemplo, que en el prólogo de la vieja Chanson de Saint Alexis se nos dice: "Ici commence une pieuse chanson qui parle du noble baron Euphémien", o el Arcipreste de Hita denuncia así su propósito: "Que pueda fazer libro de buen amor aqueste, / que a los cuerpos alegre e a las almas preste" (estr. 13).

El interés de las observaciones anteriores se deduce del hecho de que tales expresiones discursivas iniciales representan una preinformación que se da, supuesto el carácter tradicional del texto, como algo ya conocido de todos, que por lo mismo despierta la curiosidad.

\section{TRADICIÓN Y ANONIMIA}

Este acercamiento del autor al público llega a tanto que, con frecuencia, aquél se confunde con la comunidad misma, con su propio auditorio y desaparece, anónimo, inmerso en él. Cualesquiera que sean las modalidades del fenómeno, el conjunto de la literatura aljamiado-morisca, como gran parte de las literaturas románicas de la Edad Media, se nos presenta como una literatura casi totalmente objetivada, en donde el autor no aparece normalmente ante nuestros ojos. Y esto, no porque la distancia que nos separa de tales textos haya hecho olvidar el nombre de los autores, sino porque tal opacidad procede de caracteres específicos de los

${ }^{4}$ Véase Álvaro GALmÉs DE FUENTES, El "Libro de las batallas". Narraciones épico-caballerescas, t. 1, Estudio literario y edición del texto, pp. 103 y 257. 
mismos textos, transmitidos como acervo común sin otra intencionalidad, pues sólo la faz objetiva es pertinente ante el públicoauditor, no atento a escuchar, a través del mensaje poético, un habla personal, sino colectiva y tradicional. Por eso, cuando alguna vez el nombre del autor se declara, se integra en el texto y realiza una función en cierta medida publicitaria. Así, se nos manifiesta autor de su obra el morisco Ibrahim de Bolfad, quien añade "beçino de Arjel, çiego de la bista corporal, y alumbrado de la del coraçón y entendimiento"s, o en otras ocasiones sólo se nos proporciona un apelativo "El mancebo de Arévalo", del mismo modo que el autor del Libro de buen amor hace más hincapié en su título que en su propio nombre: "Yo Johán Ruyz, el sobredicho Arçipreste de Hita" (estr. 575). La autoría cuando se declara parcialmente, como en estos casos, no tiene otro objeto que crear, entre el auditor y el texto que se le proporciona, la ficción de una connivencia virtual, pero no personal. El nombre del autor es superfluo; en todo caso, es suficiente una información genérica, que permita situar el discurso en un plano de diálogo implícito. De cualquier forma, la personalidad de los autores no es accesible, ni a la crítica moderna ni sin duda al público contemporáneo, más que de forma colectiva, referida únicamente a un nivel de categorías sociológicas: ciego de la vista corporal, mancebo, arcipreste, etc.

\section{ANONIMIA Y COLECTIVIDAD}

El texto, por otra parte, de una obra tradicional, que procede de un autor anónimo, parece dirigirse, en reciprocidad a su origen, a una colectividad como tal, y no a un individuo o a un grupo de individuos aislados. El diálogo directo, tan frecuente en la épica románica, en el "roman courtois" y en la literatura aljamiado-morisca, es un expediente dramático para introducir al público en el interés de la acción y hacerle, en cierto modo, participante de ella. Pero el recurso que mejor pone de relieve el carácter colectivo del público a quien va dirigida la obra, consiste en el empleo de la persona Vosotros en los verbos ver, oír, etc., con lo que el juglar se dirige a sus oyentes para sugerirles una viva representación de lo que va a narrar:

I pasaron por un des' erto, ke no abí' a en-él peresona ni al-ǰinne (=duende, genio), i no oiri ${ }^{y}$ adeys sino el ba ramido del león (Libro de las batallas, 146; en adelante, $L B B$ ).

${ }^{5}$ Ms. de la B. N. M., núm. 9653, fol. 9r. 
I no oyérades sino $k^{\mathrm{i}}$ ridos $\mathrm{i}$ rrelinchos de kaballos, i rrelunb $\mathrm{b}^{\mathrm{a}}$ rar armas y lanças i’-espadas i baçinetas $(L B, 189)$.

En ocasiones la repetición del verbo en segunda persona del plural realza, en las descripciones narrativas, el efecto estilístico:

1 no veri ${ }^{y}$ ades sino $\operatorname{rrehmb}^{\mathrm{a}}$ rar espadas ent ${ }^{\mathrm{e}} \mathrm{r}$-ellos, $\mathrm{i}^{\mathrm{y}}$-el polvo ke pareçiy rrelánpagos en la nube; i no veri $i^{y}$ ades sino kaer enemigos a man derecha i'-a mano eçkerra $(L B, 181-182)$.

Fórmulas semejantes son también normales en las literaturas románicas de tipo tradicional, con los abundantes $o \ddot{i} e z$, o y éra$d e s$, o iríades, que van punteando el poema ${ }^{6}$.

En otro caso, la segunda persona del plural viene referida por el empleo de la partícula ve os o.ve o vos, muy frecuente en la literatura aljamiado-morisca, derivada del latín $v e-e c c e-v o s$ (cf. prov. vecbos) $>{ }^{*}$ vecbos $>$ ve ovos oveos, en donde el pronombre personal, en todo caso, hace referencia a la segunda persona del plural, y en consecuencia va dirigido hacia una colectividad, y no a un individuo. En ocasiones la repetición de $v$ e o $s$, en las enumeraciones descriptivas, sirve para acentuar la viveza expresiva:

I la ora dent ${ }^{\mathrm{a}}$ raron en-ellos una ent ${ }^{\mathrm{a}}$ rada más fư erte ke nenguna. $V e o s$ ke se ajuntaron los rrumíy es sobre la mano derecha de los muclimes; veos ke andaba este di ${ }^{y}$ a la pelea komo un molino; veos ke vino ot ${ }^{\mathrm{a}} \mathrm{ra}$ batalla de los rrumíy es muy rreziy a $(E B, 298)$.

En-esto arremetî ${ }^{\mathrm{c}}{ }^{\mathrm{A}} \mathrm{Amiru}$ ibnu al- ${ }^{\mathrm{c}} \mathrm{Abbāç,} \mathrm{i} \mathrm{los} \mathrm{ke} \mathrm{eran} \mathrm{kon-él;} \mathrm{veos}$ ke rremetìó jorjiçu kon $t^{e}$ renta mil de los del-Ärmān sobre Sarhabil ke peleaba kont $t^{\mathrm{a}}$ ra los del-Ārmān, i no kedaron kon-él sino una konpaña de sus kompañas; veos Šarhabil ke echó un kirido dixendo... ( $L B$, 310-311).

Estas series recuerdan otras análogas, introducidas con el verbo "veríais" (veriedes, veissez) de la épica española o de la francesa, en donde el efecto estilístico de la repetición está encomendado al indefinido tanto ${ }^{7}$.

TIPOLOGÍA DEL TEXTO Y DEBILIDAD DE LA AUTORÍA INDIVIDUAL

Un examen comparativo de los textos aljamiado-moriscos, como el de las literaturas románicas de la Edad Media, pone de

${ }^{6}$ Véase P. ZUMTHOR, op. cit., p. 31.

'Véase A. GALmÉs DE FuENTES, Épica árabe castellana, Barcelona, 1978, pp. 114-146. 
manifiesto que el factor de invención individual puede intervenir eficazmente respecto a la organización de los conjuntos, pero que es muy débil o difuso respecto a los "tipos", motivos temáticos o variantes del texto. La autoría individual consiste en la distribución, por otra parte dentro de límites relativamente estrechos, de los hechos particulares o "tipos", pero en los que su especie y género pertenecen a un lenguaje poético comunitario, que los determina y funcionaliza ${ }^{8}$. $O$ dicho en términos menendezpidalianos, el texto tradicional vive en variantes, que constituyen en su conjunto el acervo cultural de la comunidad, y respecto a las cuales cada autor individual puede distribuir, según reglas limitadas, ampliar o reducir, pero nunca modificar, pues ello heriría los gustos o exigencias del auditorio. De ahí la ambigüedad de los conceptos de imitación y de préstamo cuando nos referimos a textos tradicionales. El papel, pues, del individuo, en la génesis de una obra tradicional, desaparece inmerso en una tipología colectiva.

Reagrupo aquí, bajo el nombre de "tipo", siguiendo a P. Zumthor, todas las marcas formales, que relaciones parciales han designado, a veces de forma contradictoria, por los términos de clichés, topi, fórmulas, imágenes llave, motivos, etc. Un tipo, según la definición de Zumthor, será pues, como la variante menendezpidaliana, todo elemento de "escritura" a la vez estructurado y polivalente, es decir, que soporta relaciones funcionales entre sus partes, y es reutilizable indefinidamente en contextos distintos ${ }^{9}$.

\section{ALGUNOS "TIPOS" EN LA NARRATIVA ALJAMIADO-MORISCA}

A modo de ejemplo, citaré a continuación, tomando como base el Libro de las batallas, una serie de "tipos" de la narrativa aljamiado-morisca, indicando en cada caso los elementos esenciales de cada una de las clases diferentes de los "tipos".

Un contraste revelador en toda literatura tradicional es que la débil capacidad descriptiva de las imágenes literarias se asocia con una omnipresencia de la vista. En este sentido, hay que señalar la importancia del motivo de la luz, que se manifiesta en oposiciones como día/noche, claro/oscuro, en nociones como las del alba, el oro, el relumbrar de las armas o de ios rostros de las personas, etc. ${ }^{10}$, que determinan algunos "tipos" muy significativos:

\footnotetext{
${ }^{8}$ Véase P. ZUMTHOR, op. cit., p. 70.

${ }^{9}$ P. ZUMTHOR, op. cit., p. 82.

${ }^{10}$ Ibid., p. 37.
} 
Éste es kamino de $k^{a} l a r e d a d$ para kì en ki ere perender guía a tan buwena para la jente $(L B, 119)$.

I kiy eren amatar la $k^{a}$ laredad de Al.lah, i Al.lah kì ere kunpilir su $k^{a} l a$ redat, aunke pese a los desk ${ }^{\mathrm{e}}$ reyentes $(L B, 259)$.

I viyeron un alqasar muy alta; i su $k^{a}$ laredat ke rrespalandecíay a de todas partes i lugares $(L B, 331)$.

I la ora ke amaneçìó Al.lah kon la mañana, i $k^{a}$ lareó el alba, pelegó alssala ( = oración) Bilāl $(L B, 158)$.

En todos los casos anteriores el "tipo" viene determinado por la conexión entre el elemento figurativo y una concreta selección léxica (claridad) con difusas preferencias sintácticas. De otra parte, el último ejemplo citado enlaza con el tipo del amanecer, en donde a las selecciones léxicas (amanecer, buena mañana, etc.) se suma un molde sintáctico rítmico:

$\mathrm{Pu}^{\mathrm{w}}$ es kuwando amaneçżó Al.lah la bu $u^{z w}$ ena mañana, vinìeron alannabĩ ( = profeta) $(L B, 256)$.

$D-a k \imath^{y}-a$ ke amanecì ${ }^{y} \mathrm{Al}$. lah kon la bu ${ }^{w}$ ena mañana, levantóse elenemigo de Al.lah $(L B, 179)$.

"tipo" que se repite hasta la saciedad. El contraste entre el día y la noche lo podemos observar en fórmulas como las siguientes:

i t ${ }^{\mathrm{a}}$ rasnochó akella noche; i ku' ando füe en la mañana. . . (LB, 143).

Las concomitancias negativas de la noche o de la oscuridad se reflejan en "tipos" como el que sigue:

mas yo sé ke la noche es pu ${ }^{w}$ erta k-enpara la müerte $(L B, 235)$.

Otro "tipo", ligado preferentemente a una elección léxica es el que realza el brillo de determinados objetos:

I no verî́yades sino rrelunb ${ }^{a}$ rar espadas entr-ellos $(L B, 181)$.

I no oyérades sino kíridos i rrelinchos de kaballos, i rrelunb ${ }^{a}$ rar armas i lanças $(L B, 189)$.

Fizo a ${ }^{1}$ sala (= oración) kon nos el mensajero de Al.lah, i volvi' ó kon su kara la rrelunb rante $(L B, 213)$.

$\mathrm{Ku}^{\mathrm{w}}$ ando se kasó ${ }^{\mathrm{C}}$ Alï bnu abITãlib kon Fátima la rrelunb $b^{a}$ rante, no tenî́y ni abíy a en su kasa sino si ete almudes de çebada ( $L B 345$ ).

Veos en el koraçón de la weste un kaballero, ni largo ni korto; balanko, i sus pelos ke rrelunb ${ }^{a}$ raban komo el sol $(L B, 202)$.

En otro sentido el contraste entre cielo y tierra, enmarcado en un molde sintáctico-rítmico, sirve para resaltar el fragor del combate: 


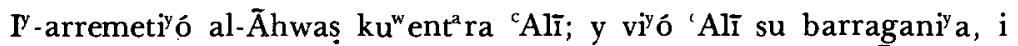

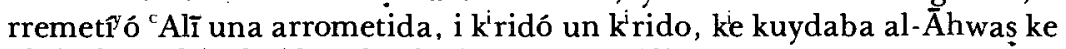
elci' elo seabi a kaido sobre la tiverra $(L B, 149)$.

I kiridó un $\mathrm{g}^{\mathrm{r}}$ ran kirido. . . ; i sentimos de la fortaleça de su voz, komo ke los ci' elos se kaîyan, o ke la tìy erra se karpi'y $(L B, 335)$.

I k' ridó un gi rito i sentimos de la fortaleza de su k'rido komo k-el çíelo se abokonase, o la tz $2^{y}$ erra se abriyese $(L B, 336)$.

I kiridó un kírido muy fíwerte, ke pensaron los de la tì erra, $k$-el $c i^{i y} e l o$ kat̂ a sobre la tîerra $(L B, 353)$.

De otra parte el polvo que cubre la claridad de la luz es otro elemento "típico", netamente lexicalizado y más débilmente enmarcado en un contexto sintáctico-rítmico, para la descripción del combate:

I no verî́ades sino rrelunb ${ }^{\mathrm{a}}$ rar espadas ent ${ }^{\mathrm{e}} \mathrm{r}$-ellos, $\mathrm{i}^{\mathrm{y}}$-el polvo ke parecíy a rrelánpagos en la nube $(L B, 181)$.

$I^{y}$-encendi óse el sol kon su kalor $\mathrm{g}^{\mathrm{a}}$ rande, $\mathrm{i}^{\mathrm{y}}$-encendi óse el rruido ent ${ }^{\mathrm{e}}$ re las westes, ke s-estordeçiy eron los kaballeros... de sus polvaredas rreçi as; ke no se pareçîy a el sol de las polvaredas $\mathrm{g}^{\mathrm{a}}$ randes $(L B, 203-204)$.

$I^{y}$-ent ${ }^{\circ}$ ró ent ${ }^{e} r$-ellos guerra fuwerte, d-akîy-a ke kubrî́y a el polvo sobrellos $(L B, 241)$.

Antes de entrar en el combate, con una o dos espadas, se describen los arreos del caballero, en un nuevo "tipo" a base de elecciones léxicas muy determinadas:

I visit'óse una kota de rraso, $\mathrm{i}^{\mathrm{y}}$-una kota de malla, güarneçida kon $\mathrm{gu}^{\mathrm{w}}$ arniç̧ ${ }^{\mathrm{y}}$ ones de oro; $\mathrm{i}^{\mathrm{y}}$-entokóse una toka amarilla, i çiñiy óse su espada, i rrankóla de la vaina; i tomó un kapaçete $(L B, 334)$.

Iy-entokóse dos tokas, la una amarilla i la otra bermeja; i çiñóse dos espadas, i tomó dos lanças, i puso en su kabeça, un kapaçete $(L B, 108)$.

I tokóse kon una toka amarilla $\mathrm{i}^{\mathrm{y}}$-otra bermeja, i çiñose dos espadas, $\mathrm{i}$ tomó dos lanzas, i tomó un kiapaçete $(L B, 113)$.

El guerrero así revestido, antes de lanzarse al combate, recita unas coplas en las que, arrogante, entona sus glorias. Es el motivo temático del fahr o de la jactancia, característico de toda la narrativa caballeresca árabe, y en el que es elemento léxico esencial la invocación a sí mismo (yo soy fulano):

Despu'és salli'ó un fijo de 'ami ( = tío) del muwerto, i dixo sus kop ${ }^{2}$ ias; i rrespuso 'AĪ̃ kon otras $k o p^{2} l a s$, i dizíy a:

- Yo soy ${ }^{\mathrm{C}} \mathrm{Ali}$, kabailero de los kaballeros, i Ai.lah gande es su fecho, $i^{y}$-éste es Muhammad, ke vì ene kon la dekª laçión; oy es el dîya del ferir i golpear $(L B, 112)$.

"l venîya un kapitán en la delantera ke se llamaba Tãriq, i deç̧̂ a sus kop las: 
-Nosotros somos los de Banĩ Fazār, más fư ertes k-el kanto de la pi"edra" $(L B, 109)$.

I salliyó en mediy o del kanpo, dixi' endo sus kopalas:

-Yö soy al-Āsyad, el konocido kon-el linaje $(L B, 113)$.

I díxoles 'Ali sus aši-räs (= coplas):

- $\mathrm{Ki}^{\mathrm{y}}$ en me konoçe, ya me konoçe; i kì en nō me á konoçido, yo me lo daré a konoçer kon mí mesmo. Yo soy 'Alï ibnu abī Țălib, el konoçido en las batallas, el kortante kon la-spada, públiko vençedor $(L B, 237)$.

Otro elemento "típico" en la descripción del combate es la "espada hiperbólica", por la que el paladín de un tajo corta al jinete de arriba abajo, y aun la espada llega a partir al caballo y se clava en la tierra gran parte de la misma:

Veos ke se levantó 'Alĩ kon-una ferida, ke le parti'ó por mediyo dos partes, i karpi ó el kaballero $i^{y}$-el kaballo, $i^{y}$-ent ${ }^{0}$ ró la-spada en la ti ${ }^{\mathrm{y}}$ erra ent ${ }^{\mathrm{a}}$ rami ${ }^{\mathrm{y}}$ ento rreçci ${ }^{\mathrm{y}} \mathrm{o}$ " $(L B, 209)$.

$Y$, sin el último detalle, véase otro ejemplo:

I firiyóle una ferida kon su espada; i partiyólo por dos partes a êl ìy-a su kaballo $(L B, 353)$.

Este motivo temático es abundante en la narrativa árabe ${ }^{11}$, y de ella, sin duda, ha sido transferido a la épica románica ${ }^{12}$.

Antes de iniciar el deber sagrado de la venganza el caballero se impone una serie de obligaciones en acumulación, a veces hiperbólica, de juramentos:

Nō beberé bebida de vaxillo ni tastaré (= probaré) vì anda enalentada, ni me envolveré mi kabeça en rropa, d-akílya ke te dé a morar en la $f^{w}$ esa $(L B, 115)$.

También éste es un tipo muy frecuente en la literatura árabe ${ }^{13}, \mathrm{e}$ igualmente transferido a la épica francesa y al romancero's.

Otro "tipo" muy característico es el del "agüero de las aves", con connotaciones léxicas muy definidas, dentro de un claro contexto rítmico semántico:

${ }^{11} \mathrm{~A}$ modo de ilustración, véanse los ejemplos que, referidos al género narrativo "al-siyár wal-magāzī", cita R. PARET, Die legendäre Maghäzi Lite ratur, Tübingen, 1930, pp. 46, 48, etc.

${ }^{12}$ Véase R. MENÉNDEZ PIDAL, La Chanson de Roland y el neotradiciona. lismo, Madrid, 1959, pp. 246-348.

${ }^{13}$ Véase E. GARCía GƠMEZ, "No comer pan a manteles... ni con la condesa holgar", AlAn, 32 (1967), 211-215.

${ }^{14}$ Véase A. GALMES DE FUENTES, Épica ärabe y épica castellana, pp. 60-63. 
I la ora de a zzuhar ( = mediodía), veos kon una águila que se puso en mitad de la karrera, i gitaba el-águila, i pikábase, i pelábase sus $\mathrm{p}^{\mathrm{u}} \mathrm{lu}$ mas; i levantóse en-el-ayre, i voló enta la çibdad d-ak̂́y-a ke se desa pareçiý de sus vistas.

I dixo Hãlid ibnu āl-Walīd, ì -él era el más sabiyo d-ellos kon la dek $^{a}$ laraçiyón de las aves:

¡Yã assihaba ( = séquito) del-annabī ( = profeta)!; esta ave nos manda y dize ke nos tornemos a la çibdad del-annabī, porke akestos enemigos nos kiy eren engañar i matarnos i kemarnos ( $L B, 161$-162).

En la épica castellana encontramos la misma variante. La Leyenda de los infantes de Salas nos da buen ejemplo de este atender a la "declaración de las aves", según la expresión del texto aljamiado; según la prosificación de la Crónica General Toledana de hacia 1460, yendo los siete hermanos con su ayo a tierra de moros, al atravesar el pinar de Canicosa, vio primero Nuño Salido dos cornejas,

... faciendo grandes agüeros, e callóselo a sí mismo./ Fueron más adelante e vido estar Nuño Salido un águila cabdal ençima de un seco pino, cómo estava desgarrándose toda, desplumpandose e sacando mucha sangre de sý misma, una águila cabdal dando muy grandes gritos vino a posar en un pino en la meatad del camino...

en tal forma que presagiaba una gran desgracia, según entiende el viejo ayo Nuño Salido ${ }^{15}$. Sorprende comprobar la estrecha relación del presagio del águila en uno y otro texto, con elecciones léxicas muy determinadas: coinciden los dos en que el águila está en medio del camino, en que el águila grita, y, sobre todo, en que se está desplumando y picando su propio cuerpo ${ }^{16}$.

Otro "tipo" está representado por la forma de dar a entender la magnificencia de un alcázar. En contraste con la situación miserable de los primeros adictos al Islam, mucho debió deslumhrar a los primeros muslimes el esplendor del mundo bizantino y de otras lujosas cortes orientales. Zaid, embajador del profeta cerca de al-Häriz, nos describe así sus impresiones de la corte del rey del Yemen:

Tuvo l-alqasar g $^{2}$ rande, i denté ré a la ptwerta del l-alqasar, i veos konuna $p^{a}$ laça muy $g^{a}$ rande en-ella; $i^{y} a b \hat{1}^{y} \mathrm{a}$ un-alqasar, y-en-ella jentes asentadas, vestidos de seda, $\mathrm{i}^{\mathrm{y}}$-en las kabezas tokas de seda kon chapas de oro, $\mathrm{i}^{\mathrm{y}}$.

${ }^{15}$ R. MENÉndez PIDAl, Reliquias de la poesía épica española, Madrid, 1951, p. 237.

16 Véase A. Galmes, "La Leyenda de los infantes de Salas y la tradición árabe", Actas de las Jornadas de cultura árabee islámica(1978), Madrid, 1981, pp.381-382. 
ent ${ }^{e}$ r-ellos un on $b^{e}$ re de $g^{2}$ rande manera; i pensé ke akél era el rrey; arreéme $i^{y}$. aparejéme para fazerle la obedençì ${ }^{y} a$, díxome akel ke dent" raba konmigo:

- No es és[te] el rrey, k-el rrey es mayor i más noble; ke akéste es uno de sus alwaziles ( $=$ ministro); i dent ${ }^{\mathrm{e}}$ ramos por otra pu erta a otra $\mathrm{p}^{\mathrm{a}}$ laga, $\mathrm{i}$ sallì ó a mí otro portero, i díxome a mí:

- ¿Tú eres mensajero de Muhammad?

Díxile:

\section{- Sí.}

Díxome:

$-\mathrm{Pu}^{\text {wes ent }} \mathrm{t}^{\mathrm{a}} \mathrm{ra}$.

I denterế kon-él a otra alqasar, mayor ke no la primera; i fallamos allí muchas jentes sobre siti ${ }^{y}$ os, $\mathrm{i}^{\mathrm{y}}$-ellos arreados, $\mathrm{i}^{\mathrm{y}} \mathrm{ent} \mathrm{t}^{\mathrm{c}} \mathrm{r}$-ellos onb ${ }^{\mathrm{c}}$ res de manera más ke no los otros; i dixe yo:

- No ay duda sino ke akéste es el rrey.

La ora ke me miró el ke iba kon-él, díxome:

- No es el rrey akéste; mas enpero akéste es un kativo de sus kativos.

I demandó liçenci' a al ke ten ̂̃y a l-alqașar otra. I dent ${ }^{\mathrm{e}}$ ré de alqașar en alqașar, de una en-otra; i de kontino pensaba ke allí estaba el rrey,

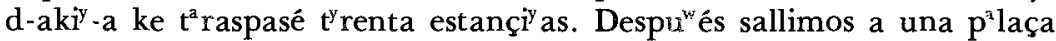
muy $\mathrm{g}^{\mathrm{a}}$ rande, $\mathrm{i}^{\mathrm{y}}$-en-ella halāqados (= criaturas) muchos, i miré a ellos; $\mathrm{i}$ veos kon-una sala: las tapiy as eran de oro, i la kub'erta de piyedras $\mathrm{p}^{\mathrm{e}}$ reçì osas i de alyaqutas (= rubíes), $\mathrm{i}^{\mathrm{y}}$-a su mano la derecha una kát $\mathbf{t}^{\mathrm{r}} \mathrm{re}$ da (= cátedra, silla $)$ de kuw emo de orifante $(=$ elefante $)$, i los piy edes aliyanbū ( = madera preciosa) esmaltada kon oro, konpu"esto kon alyaqutas $(=$ rubies $) ; \mathrm{i}^{\mathrm{y}}$-el rrey sentado en la kát ${ }^{\mathrm{e}}$ reda, $\mathrm{i}^{\mathrm{y}}$-en su kebeça tení $\mathbf{i}^{y} \mathrm{a}$ una korona de oro i de perlas, i los kostados de la korona gu" arneçidos, i los $b^{a}$ raços por lo mismo, i los alwaziles asentados delante d-él; i $\mathbf{i}^{y}$-a su mano derecha doze konsejeros, $i^{y}$-a su mano la içkerra otros tantos, kon las más nobles vestiduras i olores. Delante d-ellos i delante d-él un alkurçi $(=$ trono) de oro kon una ídola de fìy erro, i la kabeça de al-latón, i los ojos de aliyaqutas $(=$ rubies $)$ bermejas, $\mathrm{i}^{\mathrm{w}}$ en su mano eçkerra una donzella, $\mathrm{i}^{\mathrm{y}}$ en su kabeça una ave, $i^{y}$-en sus manos una kopa de oro p lena de almiçke, $i^{y}$. otra taça en su mano içkerra llena de aguw a rros (ada); i fablaba la donzella al-ave kon su lenguwaje, ${ }^{y}$-entend's'ala ell-ave; $i$ volaba ell-ave de la korona a la taça del-almiçke y-a la taça del-awa rrosada; i no dexaba ninguna kosa de-1-almiçke, ke todo lo tomaba en sus alas i pamas, y de$\mathrm{pu}^{\mathrm{w}}$ és volaba sobre la korona del rrey, i sakudîy a todo akello ke tomaba del-almiçke i del-aguw a rrosada; i tornó depuwés a la kabeça de la donzella, i hablábale otra veç, i rrosaba el-agu ${ }^{\text {a }}$ rrosada ençima de todos (LB, pp. 124-125).

Esta forma de encarecer el lujo de una corte es tópico en la li teratura árabe. Pero, aunque tópico, es significativo para es tablecer el contraste entre la penuria y el esplendor. A este respecto, es curioso observar que, cuando ya el mundo musulmán estaba en auge, había de enfrentarse en España con los nacientes reinos cristianos del Norte, repitiéndose escenas semejantes, pero en las que los papeles están invertidos. He aquî, por ejemplo, cómo Ibn Arabi de Murcia describe - en traducción que procuro 
hacer lo más literalmente posible - una embajada cristiana a la corte de 'Abd al-Rahmän III en Córdoba:

Y entró en presencia de este califa ['Abd al-Rahmán] un día, una embajada de los francos (= cristianos del nordeste de España); e hizo muestras de la grandeza de su reino de forma que les atemorizó. Extendió para ellos una alfombra, desde la puerta de Córdoba hasta la de Medina al-Zahra, distancia de una parasanga, y puso hombres a la derecha del camino y a su izquierda; en sus manos espadas largas y anchas, desenvainadas... Y cuando llegarón los cristianos a la puerta de Medina alZahra, tapizó para ellos con tela de seda desde la puerta del alcázar hasta el lugar de la audiencia, para provocar la situación de temor. Y colocó en lugares determinados a sus chambelanes, como si ellos fueran los reyes, sentados en trono adornado... Y no veían [los cristianos] a un chambelán sin que se postraran delante de él, pues se imaginaban que se trataba del califa. Entonces se les advertía:

- Levantad vuestras cabezas, pues éste es un servidor de los servidores del califa.

Y así hasta que llegaron a un patio cubierto de arena, en medio del cual estaba sentado el califa ${ }^{17}$.

Es también motivo temático "típico" la descripción de la tienda de campaña, donde se concentran los mayores lujos del beduino:

I hizo parar el rrey una tì enda para Hãlid, de seda balanka, i las kuwerdas d-ella de alharir ( = seda) verde, i las estakas de al-latón ( = cobre) bermejo kon muchos enjoyami entos de seda i de ad-ābaj ( = brocado) del más onesto de! tì enpo $(L B, 227)$.

Finalmente, reseñaré aquí, según bellísimo pasaje, el "tipo" del viento portador de mensajes, que recuerda ios reenvios (por medio de un pájaro, de la canción misma o del aire) del chant courtois, y no olvidemos que la cortesía árabe es muy anterior a la del mundo occidental:

I finkó así Hālid. I ku'wando vino la noche sobr-él, alęó, su kabeça, enta el

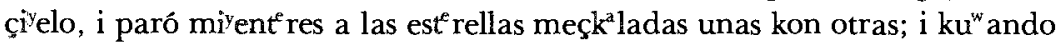
durmyeron los ojos, i no finkó en las dos kasas ( = cielo y tierra) sino el vivo mentenible, i pasó sobr-él un ayre de parte de sol poni 'ente enta el sol salliyente; i púsose a dezir akeste aši rã ( = verso):

- Kư ando oyrás, jyă ayre!, ki en hará alssala (= oración) sobre Muhammad, por Al.lahl jyã ayrel, ke los vesites a mis amados, i llégales de mĩ el-

17 IBN 'ARAB' DE MURCia, Muhädarāt al-c abrär, vol. II. El Cairo, 1905 hégira, p. 195. El texto árabe de este pasaje ha sido publicado también por $\mathrm{M}$. Asín Palacios, Crestomatía de árabe literal, Madrid, 1942, y sucesivas ediciones, núm. 23. 
a ççalam ( = saludo) ennobleçido de parte mî̀a, ke yo soy deseant a ellos, enpero áme akaeçido akaeçimì ento del tì enpo $(=$ desgracia $)(L B, 232)$.

\section{LOS CLICHÉS SINTÁGTICOS Y LÉXICOS, Y EL ESTILO TRADICIONAL}

Aunque teóricamente los clichés sintácticos y léxicos constituyen una categoría dentro de los tipos, por sus características específicas los analizo aquí en apartado independiente. Efectivamente, el "tipo" puede estar actualizado bajo una forma de expansión, por lo general descriptivamente amplificada (como ocurre con los "tipos" que he analizado hasta ahora), o bien bajo una forma condensada, alusiva ${ }^{18}$. En este último caso, el "tipo" es asimilable al "clichê", en el sentido que lo entiende M. Riffaterre ${ }^{19}$. Por otra parte, el propio Riffaterre ha puesto de relieve, frente a la crítica tradicional, el carácter positivo del cliché:

El cliché presenta la paradoja de ser agente de expresividad a causa de las mismas características que inducen a la crítica a considerarlo como un defecto... Sea cual fuere la importancia de la renovación del cliché como fuente de originalidad estilística, el cliché, para desempeñar el papel activo de un contraste creador de expresividad, no necesita en absoluto ser renovado, puesto que es la propia percepción de su trivialidad lo que le permite desempeñar dicho papel. Por último, mientras que el valor y el sentido de cualquier otro procedimiento estilístico vienen enteramente determinados por el contexto, el cliché es excepcional por cuanto su estructura lo predestina a determinadas funciones, sea cual fuere el contexto en que aparezca" (el subrayado es mío) ${ }^{20}$.

De otro lado, el cliché de la literatura tradicional comporta en sí, además de la función expresiva, una función mimética, indiferente en sí misma al propio texto, pero en el cual perpetúa la imagen, más o menos abstracta y esquematizada. Por otra razón, una diferencia considerable opone el cliché medieval al moderno. El cliché es un factor positivo del sistema poético medieval, sin el cual éste es inconcebible ${ }^{21}$.

Teniendo en cuenta las reflexiones anteriores, podemos afirmar que el carácter y el estilo tradicional de la literatura aljamiado-morisca se manifiesta también por un conjunto muy característico de clichés. En efecto, un examen atento de nuestros textos nos pone de relieve una serie de clichés innovadores,

${ }^{18}$ Véase P. ZUMTHOR, Essai de poétique médiévale, p. 95.

${ }^{19}$ M. RIFFATERRE, "Función del cliché en la prosa literaria", en Ensayos de estilística estructural, Barcelona, 1976.

${ }^{20}$ M. RIFFATERRE, op. cit., p. 217.

${ }^{21}$ Véase P. ZuMTHOR, Essai de poétique médiévale, p. 95. 
tanto en el orden sintáctico como en el léxico, generalizados en todas las obras aljamiado-moriscas, pertenecientes a cualquiera de las regiones hispánicas.

En el orden sintáctico podemos observar una serie de clichés que son calcos del árabe, y que prestan al estilo de nuestros textos un carácter especial. Esta serie está formada por un número limitado de estructuras sintácticas que se repiten en todos los textos aljamiado-moriscos sea cual sea su origen y procedencia.

Los principales de estos clichés son los siguientes: 1) Empleo absoluto del relativo ("i pasaron por un desì erto ke no abî́a en-él $\mathrm{p}^{\mathrm{e}}$ resona ni aljinne); 2) Tipo árabe mā... kāna = 'lo que tiene de...' ("i-esk ríbeme una karta kon akello ke tú as enkont'rado de la guîya"; "i yo esk ribo a tú en la suma de-ellos, sobre $\mathrm{k}^{e}$ reer $\mathrm{i}^{y}$ obedeçer, i sobre lo ke ajuntó Al.lah en-él del-ap legami ento de los ala'rabes"; 3) El pronombre personal en función de relativo ("i la ora ke llegó la nu"eva a Makka, a una fija ke tenî"a, ke se k' lamaba Hindì, ży ella rrejí a a Makka"; "veos ke vino un kaballe-

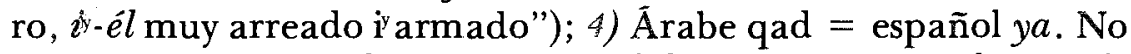
poseyendo el español recursos especiales para expresar los matices aspectivos que encierra la partícula árabe, en' la literatura aljamiado-morisca es frecuente la relación qad $=y a$, que aparece como un calco del árabe ("I ya Al.lah envi̛ó su alqư an"; "i ya Al.lah es el servidor d-ello"); 5) En otros casos, y como reflejo de una correspondencia árabe qad $=$ español $k e$, encontramos una estructura del tipo ì 'él ke, sintagma muy frecuente en nuestros textos ("ì-ellos ke se miraban komo leones ayrados"; $i y_{-}$ él ke iba enta el patitiarka"); 6) Formas tónicas del pronombre personal para expresar las relaciones de dativo y acusativo (" $\mathrm{i}$ turbará a ellos", por y les turbará; " iì envi'ó a ellos dos alamlakes"); 7) El pronombre personal en función del posesivo ("i fabló el kapitán d-ellos", por su capitán); 8) El abundante empleo del participio presente, con valor verbal, acompañado de complementos ("¿tú eres kabalgante enta la çiudad kon jentes de a kaballo i de bì en?"; "ke le jurarán kon amor, obedeçiventes o por fuerça rrecebìentes"; 9) El empleo semejante de la perífrasis "ser + adjetivo verbal en -dor" (Yo soy el matador de los millores"; "yo soy el dekalarador de los "árabes"); 10) El empleo de la copulativa en la apódosis ("La ora ke miró cAlĩ ad-aked kaballero sortir a él, $i$ púsose en mitad del kamino"; "I ku" ando amaneciyó Al.lah kon la bu" ena mañana, $i$ dixo l-annabĩ..."); 11) El uso de la copulativa con valor de simultaneidad ("i vi 6 g gü"estes muy gi randes i señas espartidas, ì -él ke deçŷa", por a la vez que él decía, mientras él decía; "volvì eron sus espaldas fuyendo, ìy-ellos 
ke llamaban kon way i kon desturuiçión"); 12) La copulativa con valor consecutivo ("Y Ya jentes!, api adevos Al.lah, $i$ Al.lah a envi"ado la verdad", por pues Al.lah ha enviado la verdad); 13) Estilo "que... que", que, tanto en los textos antiguo-españoles de traducción, como en la literatura aljamiado-morisca, aparece calcando giros semejantes del árabe ("I-era ke kada uno d-ellos $k e$ se kontaba sob re su silla por dị eç mil de kaballo"; "ke en akella noche, $k e$ soñó un su"eño"); 14) La "figura etymológica" "ensanóse ensañamivento g"rande"; "i firivó a la pu"erta firimivento lijero"); 15) Intensificación paranomásica de la indeterminación ("akeste ss un kativo de los kativos": "veos ke vino sobr ellos un rrey de los rreyes"); 16) El uso frecuente del anacoluto, forma de expresion regular en el árabe "i tomólo Allah leproso su kara"); 17) Elipus del verbo copulativo ("i comolo cnte ellos a su ami als Abace, sus manos [ Jigadas Kon kadenas"); 78) Expresión de la idea de "tener" por medio del verbo haber con preposición a ("ke no ay aparçonero a ét", por que no tiene aparçonero; "ze así ay a mí pelig ro?", por dy así tengo peligro?); 19) Frases que indican la idea de excepción calcadas del árabe ("d-akì -ke no kedó ente re él i la çibdad de Yaçariba sino kaminami'ento de un díya"; "i no salga giande, ni chiko, ni horro, ni kativo sino yo sólo"); 20) Falta de concordancia entre el verbo y el sujeto, cuando aquél precede a êste ("fasta ke no kedó delante del-annabĩ Muhammad sino divez del-asihaba"); 21) Empleo especial de algunas particulas ("ame fecho a saber mi ermano Jibul en ke vi'e. ne a nu" est ra tìerra un enemigo malino"; "atorga enta Al.lah, el.alto, Ron decir...": ke adoraban a menos de Allah", por a otro distinto gue Al hah; "komo ke huesen matulos", por como si fuesen manilos); 22) Erapleo del partivo ("iq en-êl ay de la barragani"a"); etcet

En el orden léxico también son frecuentes innovaciones (ine xistentes en la literatura de la España cristiana) generalizadas en los textos aljamiado-moriscos. Independientemente de abundantes arabismos léxicos, son numerosas las voces romances que, como novedades, aparecen sólo en la literatura aljamiado-morisca. He aquí algunos ejemplos que no están registrados en el Dic. cionario de la Academia:

aboconar 'caer, derrumbarse', afogadero 'lugar por donde un río lleva mucha agua', agladliyar 'asustar, aterrar', acontentación 'contentamiento, alegria', acoradero 'coraza', acosiguir

22 Véase A. GALMés DE FUENTEs, "Interés en el orden lingüístico de la literatura española aljamiado-morisca", CLRE(10), 2, 527-546. 
'conseguir, alcanzar', amanecimiento 'el amanecer', amoderear 'aleccionar, indicar el modo de obrar', apaganza 'satisfacción, contentamiento', apagarse "estar satisfecho, estar contento de alguien', aparzonero 'partícipe, copartícipe, compañero', aplegamiento 'ayuntamiento, reunión', asetado 'sediento', averdadecer 'hacer verdadera, hacer valedera alguna cosa', vaforear 'ech ar de sí vaho o vapor', valenteza 'valentia', bastura 'suficiente', veos y veovos 'he aquil que', de aqui a que 'hasta que', debedar 'prohibir', deritaje 'derecho, calidad de derecho, autoridad', derremir 'redimir', enalentar 'templar, calentar', enfestillar 'enderezar, levantar, dirigir", enhacendado 'solicito, diligente' (c. hacendo. so), enpara 'defensa, refugio, amparo' (en el Dic. de la Acade mia aparece empara, pero con significado distinto) enta 'a, ha. cia', esfewat 'desconfrar', especular 'distrguir a una persona con trato especial", entrar 'cohabitar", esterada "aliento, soplo", estajo 'hato, pequeño grupo de ganado' (cf. otra acepción en el Dic. de la Academia), fachal 'pañuelo o pañoleta, prenda femenina usada sobre la cabeza', forcible 'fuerte', formamiento 'figura de una persona, configuración física', fornillos 'narices', fortalado 'fortalecido', grandía 'engrandecimiento, orgullo, soberbia', guabado 'alabado', guabanza 'alabanza', iguala 'combate singular', igualar 'montar en una caballería', ivantaja, 'ventaja', capizo 'abertura que tiene cualquier ropaje para poder sacar la cabeza' (cf. cabezón, ac. $5^{\mathrm{a}}$ en el Dic. de la Academia), caminamiento "distancia, extension de camino que hay que recorrer", cautela 'añagaza', querimiento 'voluntad, deseo', la ora 'entonces, luego, al punto', lloramiento 'lloro, accion de llorar', maldignado 'mal dito', makcolpado 'malherido', mummacio 'mumullo', noncura 'negligencia, descuido', noncurante 'negligente, descuidado', noncurueño 'neglígente, descuidado', parante 'el que está parado, el que está situado', parçida 'perdón', pergonar 'proclamar', pergïeño 'almuédano', pestañadá de ojo 'parpadeo, el momento que dura el abrir y cerrar de ojos', rebibcar 'resucitar', redolear 'redolar, dar vueltas, girar', reismo 'reino, condición y oficio de rey, dignidad real', recontamiento 'narracion', reconiador 'narrador', retimblar 'blandir', semblazar 'describir, ejemplificar, asemejar', sostribar 'apoyar, descansar el peso de una cosa en algo firme', sufrencia 'sufrimiento', todora 'siempre', tremo. lar 'temblar', treta 'trecho, distancia de lugar o de tiempo', etc.

Muchas de estas innovaciones léxicas son calcos semáncicos del árabe: amoderear sobre la voz árabe' $\tilde{\alpha} d a$ 'modo, manera', de la raíz ${ }^{c} a w a d a$, que en forma $\mathbb{I I}^{2}$ significa 'habituar, acostumbrar a alguien a algo'; apaganza, que traduce literalmente el verbo 
árabe radiya; averdadecer, según ha puesto de relieve $\mathrm{R}$. Kontzi ${ }^{23}$; especialar, en relación con el adjetivo árabe $h \bar{a} s s$ 'especial' y el verbo $h \tilde{a} s s a$ 'condecorar de una manera especial, regalar'; entrar, según el doble significado del verbo árabe dahãla 'entrar y cohabitar'; igualar, calco del árabe siwāa, igual pero que en la forma VIII ${ }^{\mathrm{a}}$ significa 'sentarse cómodamente (en un caballo, en una silla)" ${ }^{\prime 24}$; cautela 'añagaza, ardid', que refleja el valor del vocablo árabe hilat, sin matiz peyorativo ${ }^{25}$; la ora, según el árabe $a l$-sac $a$ 'la hora = espacio de tiempo' y 'luego, entonces, en seguida, al punto:26, etc.

En otras ocasiones las voces moriscas están tomadas del contorno popular, escogidas por su carácter plástico y sus connotaciones afectivas, pero que no llegaron a penetrar en la lengua de los autores cultos de la España cristiana. A este grupo pertenecen voces como aboconar, afogadero, agladiyar, acoradero, acosiguir, asetado, eslenada, estajo, fachal, fornillos, grandía, guabanza, capizo, murmulicio, noncurueño, rebibcar, reismo, semblazar, sostribar, todora, tremolar, etc.

Pero lo que aquí interesa fundamentalmente es señalar, una vez más, la abundancia de giros sintácticos y vocablos innovadores en la literatura aljamiada, generalizados en todos los textos, sea cual sea su origen, formando un importante número de modelos fuertemente estructurados, pues los escritores moriscos, como ya señalé anteriormente, no practican un estilo personal, sino anónimo y colectivo, tal como se refleja en las características aquí reseñadas. Sólo acercándonos a la literatura aljamiadomorisca con estos criterios podremos valorar rectamente sus cualidades plásticas y afectivas, su belleza espontánea y no artificiosa. Desde este punto de vista, hay que considerar que la tradición (como concibió desde siempre Menéndez Pidal), constituye un verdadero a priori de la realidad poética, según recuerda $\mathbf{P}$. Zumthor. En tal sentido, uno de los rasgos, en efecto, más significativos de la literatura tradicional es la extrema estabilidad (como trato de significar para los textos aljamiados), a lo largo del tiempo y en el conjunto del "corpus" de términos condicionados por el carácter colectivo de la producción textual ${ }^{27}$.

28 "Calcos semánticos en textos aljamiados", Actas del Congreso Interna cional sobre literatura española, aljamiada y morisca, ed. A. Galmés de Fuentes, Madrid, 1978, pp. 329-331.

${ }^{24}$ Cf. R. KONTZI, art. cit, pp. 325-326.

${ }^{25}$ Véase A. GALMÉs DE FUENTES, Épica árabe y épica castellana, pp. 72-73.

${ }^{26}$ Véase A. CALMÉS De Fuentes, París y Viana, p. 236.

${ }^{27}$ Para el análisis que aquí he realizado me he basado en textos narrativos, 
EL ESTILO

El estilo general de la literatura aljamiado-morisca concuerda bien con estas características que acabo de analizar.

Ante todo, la literatura aljamiado-morisca tuvo, como ya he señalado, una difusión colectiva a través de un cultivo tradicional y anónimo, rehaciendo sus obras en continuos tipos o variantes y frecuentes refundiciones - de las que en muchas ocasiones se nos conservan varias - , cuyos autores no practican un estilo personal, sino anónimo y colectivo. Dentro de esta tradicionalidad, el arte de nuestros textos es, en efecto, elemental y sobrio, pero no por ello menos flexible y expresivo. No encontramos en él la variedad estilística ni la complejidad que ofrecen otros textos más artificiosos. Su tonalidad puede ser a veces apagada y aparentemente gris, pero las descripciones adquieren expresividad cuando se refieren a un lenguaje poético comunitario, como ocurre en el caso en que los temas reflejan sentimientos específicos. Pero, en todo caso, el arte de esta literatura tradicional posee severidad de sentimiento, y el abundante diálogo en el frecuente estilo directo - nota, por lo demás, característica de toda la literatura árabe - da viveza a la narración. De otra parte, en su aparente elementalidad, el estilo de la literatura aljamiado-morisca alcanza notas delicadas. Refiriéndose a un texto, a modo ejemplificador, el Libro de las batallas adopta un acento sentido y tierno en las escenas familiares (en las relaciones entre 'Alī y Fãtima, entre ésta y su padre, entre Mahoma y sus nietos, etc.), o en los lazos de lealtad entre Mahoma y sus súbditos: "Yā Muhammad - dice, por ejemplo, Abū Bakr - nosotros somos tuspada la tajante, i tu lança la kunpilida, i tus piyed'ras esmenuzantes, i tus saetas furì entes, i tus kaballos korriventes, ke feriremos i ferirnos-an, d-akír-a ke mu"era ent' ${ }^{\mathrm{t}}$ - tus manos" (fol. $62 \mathrm{r})$; refleja sentidamente la emoción y la ternura que las palabras de Mahoma despiertan entre sus seguidores: "I viniy eron las jentes d-aký-a ke se inchó la meçkida, i 1-annabĩ (= profeta) puyó al-almi[m]bar (= púlpito), i fizo alhuṭ $\mathbf{b a}^{\mathrm{b}}(=$ una plática $)$ muy kunpilidamente, ke s-enrrasaban d-ella los ojos de aguwa, i $\mathrm{k}^{\mathrm{a}}$ lareaban los qorazones de deseo del-al-janna $(=$ paraiso) i de temor del fuwego" (fol. 2irr); se emplea un acento irónico al

pero procedimientos análogos se utilizan también en la literatura religiosa aljamiado-morisca, como puede deducirse del trabajo publicado en este mismo volumen, pp. 441 ss. de Mercedes Sánchez, "La lengua de los manuscritos aljamiado-moriscos como testimonio de la doble marginación de una minoría islámica". 
describir ardides o engaños de guerra que, aunque partan de las huestes de Mahoma, en ningún caso se tratan de ocultar: un guerrero bizantino, en la batalla de Yarmūk, recrimina al paladîn musulmán Šrhabíl:

- ¡Yã kaballero!, sie emp re tentáys en-engaños en la guerra.

Dixo Sarhabīl:

- Way de tú! ¿I no sabes ke la guerra k-es toda engaños? (fol. 14lv);

o hace gala de un estilo querelloso, como ocurre en la leyenda de 'Alĩ con las cuarenta doncellas, para romper con increíble energía en las descripciones de batallas o combates singulares, ofreciendo cuadros vivos y exactos de los famosos trances de guerra, animados por acertados toques de violencia y dinamismo, que parecen descritos por un testigo presencial de los sucesos:

La ora mandó Abu'Ubayda mudarse a las jentes, i dixo Abu'Ubayda a Hãlid:

- Toma tu weste, i sey en la warda de los muçlimes, mì ent ${ }^{\mathrm{e}}$ res se mudan las jentes.

I oyeron los desk ${ }^{c}$ reyentes el rruido de los muçlimes en su mudamiento, iyakuytáronse los rrumîy es a ellos.

I kuw ando los vìo Hálid, giritó kon sus kaballeros, i dixo:

- Esta es la seña del-ayuda.

I rrankaron las espadas, i kon él al-Hirqal, i Ḍirād ibnu al-Āzwār, i Talhata, $i^{c}$ Amiru ibnu a-Tufayri. I kometì eron los muçlimes kont ${ }^{\mathrm{a}}$ ra los desk ${ }^{e}$ reyentes; i volvi' eron fuyendo los rrumiyes, fasta el rrîyo del-Ardun; i fundi' éronse muchos desk ${ }^{e}$ reyentes, por fuir de los muçlimes.

I la ora asentó $\mathrm{Abu}{ }^{\mathrm{C}} \mathrm{Ubāyda}$ en el Val Yanbuk; ì -era un kabeço muy $g^{\mathrm{a}}$ rande, $\mathrm{i}$ dexó Abu 'Ubayda a las mujeres i k riaturas en el kabeço; $\mathrm{i}^{\mathrm{y}}$ aturaron allí los muçlimes, aparejando sus armas para pelear. I los enemigos de Al.lah ke llegaban, iy -asentaron su rreal.

Veos ke se açerkaron de los muçlimes en-un val muy rriko, ke se llamaba al-ǰawlān. I ku'wando vi'eron los muçlimes la muchedunbere de los rrumiy es, akongoxáronse; $\mathrm{i}^{y}$-ellos ke demandaban ayuda a Al.lah, el $\mathrm{g}^{\mathrm{a}}$ rande.

Iy era ke abîy a mandado el-enperador Hirkal a los rrumŷy es ke no kometi $i^{y}$ esen pelea nenguna, sino ke p $^{\mathrm{i}}$ rimero kometi ${ }^{\mathrm{y}}$ esen partido, i los llamasen a igu" ala ( = combate singular $)$.

İy -envi'ó Mãhãn a J̆orje mensajero, ìaçerkóse Jorje çerka del rreal de los muçlimes, i díxoles:

- ¡Yã konpaña de al'árabes!, salga a mí el kaoitán, fasta ke oyga mi [mi] mensajería.

I salì'óle Abu 'Ubayda, i díxole:

- ¿Ké demandas? yyã kãfir (= infiel $) !$

Dixo Jorje:

- YYã kapitán! No nos engañéys kon dezir ke abéys vençido i ganado las tì erras de Ašãm. Mirad agora a lo ke está delante de vosotros.

Dixo Abu 'Ubayda: 
- No emos mi edo a vu ${ }^{\mathrm{w}}$ estro muchidunb ${ }^{\mathrm{e}}$ re, ni a vu' est ${ }^{\mathrm{e}}$ ras espadas en la guerra, ke nosotros eso buskamos. I no ay duda sino ke nos emos d-

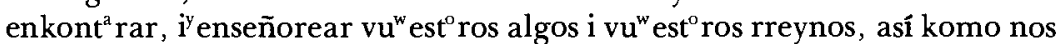

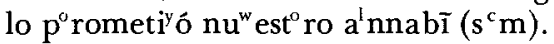

Siguiendo con la ejemplificación del Libro de las batallas, dentro de un carácter ampliamente humano, los héroes del Islam aparecen revestidos de elevación moral y de mesura, dispuestos al perdón de sus enemigos; la lucha del Islam naciente, tal como se refleja en el singular texto aljamiado, contra los infieles se consuma con la mayor tolerancia; la ira y la pasión de venganza, reflejada en algunos pasajes, sólo hallan cuerpo entre los infieles. Trátase, por lo demás, de un conflicto social que refleja las aspiraciones democráticas de la doctrina de Mahoma, reconocidas hasta por sus propios enemigos. Un consejero áulico del rey al-Háriz declara, en el referido Libro de las batallas, ante su soberano:

$\mathrm{Pu}^{\mathrm{w}}$ es yo tengo çi ${ }^{\mathrm{y}}$ ento i té renta años, ke no é visto ni-é oído semejante de akeste onb're, Muhammad ibnu 'Abdi Il.lahi; porke él es kunpilido en-el seso, de bu' en konocimi ento, i de bu ${ }^{w}$ en konsejo, i kome ordito (es decir, comida pobre), $i^{y}$-el pobre $i^{y}$-el rriko enta él son igu ${ }^{w}$ ales... (fol. 19r).

Espíritu democrático que no podían tolerar magnates como el rey gassani, Jabala b. al-Ayham, convertido al Islam, pero no identificado con su doctrina, que ante el conflicto de un pobre beduino, resuelto judicialmente a favor de éste, reniega de la religión musulmana, volviendo a su antigua creencia.

He acumulado intencionalmente algunos ejemplos, con ánimo de dar idea de la realidad estilística de este tipo de literatura tradicional. Frente al formalismo y la estilización de obras literarias eruditas de autor individual, de propósitos deliberadamente estructurados, el arte de la literatura aljamiado-morisca deja una impresión de espontaneidad a la que no es ajena su lenguaje de tono popular y aun dialectal. Así, el Libro de las batallas, como muchos otros relatos y textos narrativos, ofrece, en el corpus de la literatura aljamiada, un espécimen perfecto de una narración continua, variada, entreverada por abundantes diálogos, y que progresa a veces con lentitud, a veces de forma acelerada, por la sugerencia de un detalle, que, si estuviese apoyado, retendría el ritmo, la evolución del conjunto.

En general, la ley artística de la literatura aljamiadomorisca, como la de muchas obras de literaturas tradicionales románicas de la Edad Media, pudiera concretarse en la libre 
combinación espontánea de lo narrativo con lo dramático y, en más escasa medida, con algunos momentos líricos.

Por todas estas razones, nos encontramos en la actualidad, ciertamente, muy lejos de la valoración romántica de la literatura aljamiado-morisca. Cuando, en la primera mitad del siglo XIX, se descubren y ponen en juego algunas obras de los moriscos, la mentalidad de los románticos encarece el interés de tales escritos en términos que hoy día no podemos compartir. Así, por ejemplo, el conocido escritor Serafín Estẻbanez Calderón, en el Discurso pronunciado en la apertura de la cátedra árabe del Ateneo de Madrid, el día 12 de noviembre de 1848, se expresa de la siguiente manera: "El que esté hastiado de la literatura del día, no tiene más que abrir las puertas por medio del árabe a la literatura aljamiada, verdadera América por descubrir".

Naturalmente, quien pretenda, hoy día, encontrar en la literatura aljamiado-morisca un Potosí novelístico o un Cervantes islámico, un Shakespeare o un Erasmo, yerra, como crítico, el camino a seguir para la recta comprensión de los valores literarios intrínsecos y del encanto que encierran nuestros textos. Sólo teniendo en cuenta las diferentes normas estéticas que regulan la obra literaria de tipo tradicional con respecto a la obra más artificiosa de autor individual, podremos comprender el verdadero alcance literario de los textos aljamiado-moriscos. En ese sentido, es evidente que no podemos despreciar el texto tradicional, según el manuscrito oxoniano, de la Chanson de Roland, frente al poema erudito del Orlando furioso, por el hecho de que este último sea obra de un autor individual conocido, como Ariosto; del mismo modo que no podemos relegar un romance tradicional, como el de El Conde Arnaldos, ante otro romance artificioso aunque sea de un autor renombrado (Lope, Góngora). Quiero decir, que existen moldes muy diferentes para enjuiciar y acercarse, respectivamente, a la literatura colectiva de tipo tradicional y a la literatura individual más artificiosa. Y aplicar métodos válidos para el análisis de un texto individual a los textos tradicionales, significaría desfigurar radicalmente las realidades estéticas y estilísticas.

Ahora bien, si, como acabo de indicar, la mayoría de los textos de la literatura española aljamiado-morisca son de estilo tradicional, también entre los moriscos se practicó deliberadamente un tipo de literatura individual más artificiosa, al que podemos y debemos aplicar sus propios y peculiares métodos. Tal es el caso de un notable soneto de un morisco tunecino, que bien puede figurar al lado de los más dignos de nuestro Siglo de Oro: 
Dios, que a los suyos padeciendo mira muerte en la bida y en el cuerpo ynfierno por pecados de padres sin gobierno, o por la causa que a su globo admira, alça la ardiente espada de su yra; y como criador y amante tierno no es, siendo eterno, en la bangança eterno, que al descanso, piadoso la retira:

Del Faraón de Spaña ablanda el pecho, y a su pesar les da en el mar camino, que stá de berdes flores prado hecho; $y$ en buestro yngenio raro y peregrino dándole luz de Dios tanto probecho que ya no soys mortal, sino dibino.

En otra ocasión he comentado, con mayor o menor fortuna, este poema de la misma forma que habría comentado, por ejemplo, un soneto de Góngora ${ }^{28}$. Y es evidente que nuestro morisco sale airoso, y bien airoso, de la prueba crítica.

\section{Álvaro GALMÉs de FuENTES}

Universidad de Oviedo.

${ }^{28}$ A. GALMÉS DE FUENTES, "Sobre un soneto barroco de un morisco", en $A O, 27 / 28$ (1977-78), 201-217. 